Germanistische Abhandlungen

Drama Liebe 
JUTTA GREIS

\section{Drama Liebe}

Zur Entstehungsgeschichte der modernen Liebe im Drama des 18. Jahrhunderts 


\section{GERMANISTISCHE ABHANDLUNGEN 69}

\section{CIP-Titelaufnahme der Deutschen Bibliothek}

\section{Greis, Jutta:}

Drama Liebe : zur Entstehungsgeschichte der modernen Liebe im Drama des 18. Jahrhunderts / Jutta Greis. - Stuttgart : Metzler, 1991

(Germanistische Abhandlungen; 69)

ISBN 978-3-476-00753-7

NE: GT

ISBN 978-3-476-00753-7

ISBN 978-3-476-03357-4 (eBook)

DOI 10.1007/978-3-476-03357-4

Dieses Werk einschließlich aller seiner Teile ist urheberrechtlich geschützt. Jede Verwertung außerhalb der engen Grenzen des Urheberrechtsgesetzes ist ohne Zustimmung des Verlages unzulässig und strafbar. Das gilt insbesondere für Vervielfältigungen, Übersetzungen, Mikroverfilmungen und die Einspeicherung und Verarbeitung in elektronischen Systemen.

(C) 1991 Springer-Verlag GmbH Deutschland Ursprünglich erschienen bei J.B. Metzlersche Verlagsbuchhandlung und Carl Ernst Poeschel Verlag GmbH in Stuttgart 1991 
1. Die Liebe in den Zeiten der Postmoderne 1

2. Die Literatur des 18. Jahrhunderts und die Liebessemantik 3

3. Liebe in kulturhistorischer Perspektive - Forschung und neue Fragen 5

4. Liebe: Diskurs, Semantik, Code, Topos 13

5. Zur Textreihe 15

ERSTER TEIL

II Vom Gesetz der Allianz zur Freiheit der Liebe. Die Entstehung $\begin{array}{ll}\text { des Liebesdiskurses und die Entfaltung seiner inneren Semantik } & 18\end{array}$

$\begin{array}{ll}\text { Einführung } & 18\end{array}$

1. Literarhistorische Vorgeschichte: Gottscheds "Schaubühne" 22

Die ungleiche Heirath (1743) 22

Das Testament (1745) 24

Der Hypochondrist (1745) 25

2. Erste Konturen neuer Subjektivität und Intersubjektivität.

$\begin{array}{ll}\text { Liebe und Empfindsamkeit versus Allianz } & 27\end{array}$

$\begin{array}{ll}\text { Die Betschwester (1745) } & 27\end{array}$

Das Loos in der Lotterie (1746) 30

Die zärtlichen Schwestern (1747) 34

Der Freygeist (1749) 40

3. Liebestopos in Trauerspiel und Schäferspiel 42

Canut (1746) 42

Atalanta (1741) $\quad 44$

Sylvia (1745) 44 
Einführung $\quad 50$

1. Die Liebe wird tragisch. Frühes bürgerliches Trauerspiel 52

Miß Sara Sampson (1755) $\quad 52$

$\begin{array}{ll}\text { Lucie Woodvil (1756) } & 60\end{array}$

$\begin{array}{ll}\text { Julie (1767) } & 62\end{array}$

2. Extrapolation auf die Gesellschaft. Liebe, Empfindsamkeit, $\begin{array}{ll}\text { Allianz und Politik } & 66\end{array}$

$\begin{array}{ll}\text { Rhynsolt und Sapphira (1755) } & 66\end{array}$

Lady Johanna Gray (1758) $\quad 68$

$\begin{array}{ll}\text { Codrus (1758) } & 70\end{array}$

3. Historische Irritationen. Rekonstruktion von Liebe und Empfindsamkeit

Minna von Barnhelm (1769) 74

\section{ZWEITER TEIL}

Einführung

IV Die Etablierung der empfindsamen Liebe - Anknüpfung an die sechziger Jahre

Clavigo (1774) 84

Die Reue nach der That (1775) $\quad 86$

$\begin{array}{ll}\text { Mariane (1776) } & 87\end{array}$

$V$ Mord und Totschlag. Die Familie als scheiternde empfindsame

Gemeinschaft oder: Diskursunfälle von Liebe und Empfindsamkeit 89

Die Zwillinge (1776) 91

Julius von Tarent (1776) $\quad 92$

Die Räuber (1781) 95

VI Das große Tabu und die Regungen des Begehrens. Zur Entstehung des modernen 'Sexualitätsdispositivs' aus den Aporien der empfindsamen Liebe 103

$\begin{array}{ll}\text { Emilia Galotti (1772) } & 103\end{array}$ 
1. Privatheit, Gesellschaft, Politik. Der Liebestopos im Geschichtsdrama

Die Verschwörung des Fiesko zu Genua (1783) 123

$\begin{array}{ll}\text { Dom Karlos (1787) } & 128\end{array}$

Egmont (1788) 133

2. Liebe versus Humanität? Die Dissoziation von Liebe und $\begin{array}{ll}\text { Empfindsamkeit als Rettungsstrategie } & 136\end{array}$

$\begin{array}{ll}\text { Nathan der Weise (1779) } & 136\end{array}$

$\begin{array}{ll}\text { Iphigenie auf Tauris (1787) } & 138\end{array}$

IX Reparaturspiele: Immanente Korrekturvorschläge am Liebesdiskurs 142

$\begin{array}{ll}\text { Die Laune des Verliebten (1779) } & 142\end{array}$

$\begin{array}{ll}\text { Stella (1776) } & 144\end{array}$

Menschenhaß und Reue (1789) $\quad 147$

Die edle Lüge (1792) 149

$\begin{array}{lr}X \text { Integrationsstrategien und Wunschbilder } & 151\end{array}$

Der adliche Tagelöhner (1774) 153

Nicht mehr als sechs Schüsseln (1780) 155

Der teutsche Hausvater (1780) 156

$\begin{array}{ll}\text { Verbrechen aus Ehrsucht (1786) } & 158\end{array}$

Bewußtseyn (1788) 159

Das Kind der Liebe (1790) $\quad 160$

XI Poetische Retrospektive 163

$\begin{array}{ll}\text { Wallenstein }(1799 / 1800) & 163\end{array}$

XII Historische Illustration und Brücken zur Gegenwart $\quad 172$

1. Goethes unglückliche Schwester. Allianz, Liebe und Identität $\begin{array}{ll}\text { - eine historische Illustration } & 172\end{array}$

2. Brücken zur Gegenwart. Die Macht des Diskurses 176

$\begin{array}{lr}X I I I & \text { Anmerkungen } \\ & 184\end{array}$

$\begin{array}{lll}X I V & \text { Literaturverzeichnis } & 248\end{array}$ 